artigo $]$

[ ISABELA MONKEN VELLOSO ]

Doutora em Ciência da Literatura (UFRJ), mestre em Teoria Literária (UFJF), especialista em Moda, Cultura de Moda e Arte (UFJF). Professora Adjunta do Instituto de Artes e Design da UFJF.

E-mail: isamonken@uol.com.br

\title{
Floratta: o figurino e a sedução dos sentidos'
}

\author{
Floratta: the costume and the \\ seduction of the senses
}

[resumo] Neste artigo, buscou-se refletir sobre a prática do figurino e dos gestos na construção das narrativas vinculadas às fragrâncias Floratta Cerejeira em Flore Floratta Cerejeira em Pétalas, ambas pertencentes à marca 0 Boticário. Como espaço de investigação discursiva, destaca-se o filme publicitário Árvore, desenvolvido pela agência AlmapBBDO.

[abstract] In this article, we tried to reflect on the practice of costumes and gestures in the construction of narratives linked to Floratta fragrances Cherry Tree In Bloom and Floratta in Cherry Petals, both belonging to the trademark 0 Boticário. As a discursive space of research, there is the advertising film Tree, developed by agency AlmapBBDO.

[keywords] costumes; Floratta Cherry; speeches; senses; perfumes. 
Introdução

"O trabalho criativo exige identificação corporal e mental, empatia e compaixão." Juhani Pallasmaa ${ }^{2}$

A emoção se instaura pelos caminhos do corpo: nele todos os sentidos convergem sem fronteiras. No livro Filosofia do odor, Chantal Jaquet (2014) destaca a obra Noa Noa de Paul Gauguin - termo que na língua maori refere-se àquilo que é odorífero -, espaço no qual o artista evoca a pintura olfativa, o cheiro pela cor. Para Gauguin, a condição do sentir ultrapassa a ação de simplesmente olhar, o que reforça seu chamado para a interioridade do odor. Debussy, por sua vez, no livro I, Prelúdios, suscita o casamento da música com as fragrâncias. Podemos, igualmente, pensar em outras convergências, tais como as esculturas olfativas, ainda que a solidez dos materiais possa sugerir um aparente contrassenso (JAQUET, 2014). Lembremos das palavras de Alberto Caeiro: "Penso com os olhos e com os ouvidos. E com as mãos e os pés. E com o nariz e a boca. Pensar uma flor é vê-la e cheirá-la. E comer um fruto é saber-lhe 0 sentido" (PESSOA,1974, p.146). Proust, por sua vez, converge no Volume I de Em busca do tempo perdido, No caminho de Swann, o sabor das madeleines e os cheiros do chá às memórias e às narrativas de tempos pregressos.

Para a reflexão acerca dos perfumes e dos figurinos, cabe ressaltarmos o acionamento da visão periférica em detrimento da visão focal ${ }^{3}$. Ainda que vivamos a era das especializações e das múltiplas fragmentações, o corpo, no trajeto de constituição dos sentidos, buscará sempre os gestos holísticos. Cheiram-se palavras, veste-se a nudez; nas cores, temperaturas são encontradas; com a língua e seus sabores narram-se imagens. Pode-se afirmar que a escritura e a leitura são narrativas do corpo; e ainda que a descoberta da escrita tenha, em certo aspecto, contribuído para a primazia da visão e certo amortecimento da força sinestésica da oralidade, certamente escrevemos e lemos acionando todos os nossos sentidos. Sobre as convergências sinestésicas na apreensão das linguagens do mundo, retomamos o pensamento de Goethe (apud PALLASMAA, 2011, p. 13): "As mãos querem olhar, os olhos querem acariciar".

No presente estudo, procuraremos refletir sobre a utilização do figurino na constituição das narrativas que envolvem as fragrâncias Floratta Cerejeira em Flor e Floratta Cerejeira em Pétalas, desenvolvidas pela marca 0 Boticário. Como espaço de investigação, destaca-se o filme publicitário Árvore (2013), realizado pela agência AlmapBBDO para divulgar as referidas fragrâncias".

As narrativas de Floratta Cerejeira

"A língua olfativa é tão sutil e insinuante quanto a língua literária, pois ela penetra o homem sagaz, envolve-o e o circunda, instilando eflúvios ora tênues, ora tenazes."

Chantal Jaquet, Filosofia do odor ${ }^{5}$

Quando a floração da cerejeira se inicia, é sinal de que o inverno termina e é chegada a primavera. São essas as indicações de uma flor que, na cultura japonesa, representa a feminilidade, a renovação e a energia. Signo de transformação, a flor de cerejeira - sakura - orienta ao Hanami: ato de contemplação da beleza das flores. A floração da cerejeira é ansiosamente aguardada no Japão e, normalmente, não ultrapassa duas semanas, período em que ocorrem os festejos do Hanami. Pelo curto período de sua floração, a cerejeira também é concebida como símbolo da efemeridade, associando-se ao bushido - código samurai - e à sua crença na importância de viver plenamente o tempo presente. 
Conforme a lenda descrita no site de 0 Boticário ${ }^{6}$, a princesa Sakuya teria caído do céu, na região do Monte Fuji, convertendo-se na flor de cerejeira.

Inspirados nessa flor, perfumistas da Symrise desenvolveram para 0 Boticário as fragrâncias Floratta Cerejeira em Flor, criação de Joaquim Correl, e Floratta Cerejeira em Pétalas, concebida por Alexandra Carlim. Ambas foram lançadas em 2013. De acordo com a descrição do site 0 Boticário, Floratta Cerejeira em Flor constitui um floral, oriental, fresco. A proposta da fragrância é evocar a beleza e a delicadeza da flor de cerejeira, com notas de ousadia e esperança. Este é convite da marca que, em seu site, também nos revela a escritura olfativa de Floratta Cerejeira em Flor:

\begin{abstract}
Em Floratta Cerejeira em Flor temos [notas de saida]: acorde frutal fresco: mandarina, frutas silvestres, damasco. Em Floratta Cerejeira em Flor temos [notas de corpo]: lírio do vale, muguet, madressilva, gardênia, jasmim, flor de laranjeira. Em Floratta Cerejeira em Flor temos [notas de fundo]: sândalo, âmbar, praline, musk, caramelo.?
\end{abstract}

$\mathrm{Na}$ análise de tais composições, segundo as informações disponiveis, podemos notar que, curiosamente, na descrição das notas, não há nenhuma menção específica à cerejeira, mote da fragrância. 0 site da Osmoz destaca a inexistência de um óleo essencial da cerejeira, tratando-se portanto de um resultado obtido da sintese de outras substâncias:

Não é possível obter o óleo essencial diretamente da cereja. Seu perfume é reproduzido em laboratório através de combinações de diferentes moléculas. 0 benzaldeído, com forte aroma amendoado, possibilita especialmente a reprodução da nota da noz da cereja. ${ }^{8}$

Já na versão Floratta Cerejeira em Pétalas, temos um floral buquê. Trata-se de uma versão genuinamente floral, no sentido de que as notas florais são preponderantes na estrutura do perfume. Para a versão "Em Pétalas" do Floratta Cerejeira, as notas de saída são as mais voláteis, que respondem pelas percepções iniciais: "folhas de bambu, lírio do vale, acorde especiado fresco, maçã, lichia e pimenta rosa" (O BOTICÁRI0,15/5/2015). Nas notas de corpo, as menos voláteis, responsáveis pela identidade da fragrância: "violeta, freesia, muguet, gardênia, cereja, flor de osmanthus, cedro branco". (0 BOTICÁRIO, 15/5/2015). Nas notas de fundo, as que permanecem mais tempo na pele, harmonizando-se com as demais, e que apresentam maior peso molecular: "cedro, sândalo, musk, vanila, fava tonka e musgo de carvalho" (O BOTICÁRIO, 15/5/2015).

Pode-se observar na descrição olfativa do anunciante que, na composição da versão "Em pétalas", a cereja se faz presente nas notas de corpo, que conferem à fragrância sua maior expressividade. Entretanto, sabe-se que, no âmbito da perfumaria, a fragrância de inspiração raramente surge de forma pura: o seu aroma, normalmente, é um convite a um contexto simbólico e sinestésico, não se tratando de uma tradução literal.

Além de sua orquestração aromática, as fragrâncias solicitam uma roupagem que Ihes dê forma, reafirmando seus simbolismos, instaurando-os ou até mesmo identificando-os. Nesse contexto, destacam-se os frascos e as embalagens. Nos frascos anteriores da linha Floratta, de 1995 a março de 2012, as flores, símbolos da natureza tropical, vinham ricamente cravejadas, na versão do designer Thierry Lecoule. No âmbito da linha Floratta, em sua mais recente visualidade - diferenciando-se dos frascos anteriores, de traços rococós - pode-se notar a presença de uma estética contemporânea, que sugere leveza e luminosidade. Nas novas versões, o perfume torna-se a própria flor ao desabrochar, resultado do trabalho de repacking elaborado pela Narita Design?. Atualmente, na linha permanente da categoria Floratta, destacam-se Floratta in Blue, floral musk, concebido em 1998 pelo perfumista Napoleão Bastos, da International Flavors \&t Fragrances Inc. (IFF); Floratta in Gold, um floral muguet, 
desenvolvido em 1999 por Sophia Grojsman (IFF); e o Floratta in Rose, floral buquê, criado em 2005 por Verônica Casanova, também da IFF.

Para o comercial em vídeo e os materiais publicitários impressos da linha Floratta Cerejeira, o Boticário contou com a equipe da AlmapBBD0, agência de publicidade que desenvolve produções para 0 Boticário desde 0 ano de 2004. Sobre os materiais impressos para a campanha de Floratta Cerejeira, seguem os informes da agência:

\footnotetext{
A campanha para jornais e revistas, fotografada pelo francês Christophe Rihet, em Paris, tem por objetivo mostrar, por meio das imagens, a leveza e a delicadeza das novas fragrâncias, revelando o significado da flor de cerejeira. As peças utilizam toda a beleza da modelo francesa Leonore Masson (Metropolitan Paris), e da italiana Giulia Berreti (Evidence Models), em imagens que unem a atitude das mulheres modernas à delicadeza e à feminilidade. Toda a maquiagem e o figurino dos anúncios foram cuidadosamente escolhidos para passar as mensagens das novas fragrâncias. Eles têm tons de rosa e salmão, que remetem aos frascos dos perfumes. Para buscar o vestido ideal, a equipe de produção foi ao estúdio da ex-modelo Anoushka, sucesso durante os anos 80 e que, desde o início da carreira, coleciona vestidos e sapatos vintage de alta-costura. 0 estúdio de Anoushka é uma referência para os amantes e profissionais de moda e de figurinos de alta qualidade. Lá, foi eleito o vestido salmão da maison Carven, dos anos 50, que representará a fragrância Cerejeira em Pétala ${ }^{10}$.
}

Como podemos notar, a campanha impressa resultou de esforços criativos que não deixam de entrever a importância do traje de cena na constituição das imagens. No site da agência, até o presente momento, não se observou, entretanto, o registro específico dos profissionais de figurino nos dados da ficha técnica das imagens impressas. Pode-se observar nas imagens, muito bem concebidas, como a textura da roupa evoca a superfície da flor, suas pétalas, numa nítida junção sensorial.1"

0 filme Árvore, de aproximadamente 30 segundos, teve a direção geral de Luiz Sanches, a direção de Alex Gabassi e Ricardo Della Rosa - também responsável pela fotografia. ${ }^{12}$ A narrativa inicia-se com sons que parecem dialogar com orquestrações de meditação budista e a câmera insere-se diagonalmente na imagem, sendo a cena paulatinamente apresentada do ponto de fundo - o telhado de um templo - ao centro. No vídeo, vislumbra-se um lago com neblina, tal como aquelas do amanhecer, e uma mulher que, com suas mãos, direciona o remo de uma pequena canoa. Já na abertura do filme, pode-se observar como a imagem evoca a textura das substâncias líquidas e vaporosas.

0 telhado do templo Kinkaku-Ji (Itapecerica da Serra) parece estar molhado, assim como o áudio reproduz sons cuja acústica lembra sonoridades úmidas, vaporosas e aquáticas de bambus como os utilizados em mensageiros do ventos. Os sons são fluidos, límpidos, favorecendo a imersão em técnicas meditativas. A abertura da narrativa já sinaliza seu enredo.

A mulher destacada na imagem não é uma figura comum. Trata-se da modelo brasileira Eloise Yamashita (AZ Models), jovem, longilínea, magra, muitíssimo elegante e delicada, que parece saber exatamente como direcionar seu olhar, seus gestos e a canoa por ela conduzida, construindo uma imagem de suave deslocamento e deslize. As neblinas e o direcionamento da câmera que surge do plano de fundo da imagem favorecem a sensualidade e o tom misterioso da abertura do filme, tornando o olhar do espectador um tanto intrusivo, voyeur.

Outro dispositivo de sensualidade para a exploração dos sentidos, muito utilizado nos códigos de strip-tease, é a lentidão, observada tanto nos gestos da personagem 
quanto no passeio da câmera pelas tomadas. Assim como a lentidão, a umidade e o brilho vaporoso e comedido das cenas mantêm o caráter envolvente da imagem lembremos que o prazer corpóreo é irmão da umidade e dos líquidos. A sensualidade aqui evocada, entretanto, se dá por signos depurados e sutis que em nada falam de códigos estridentes. 0 poder aqui é dado ao mínimo, o mínimo do gesto, o mínimo da cor, o mínimo do traje, conferindo ao intérprete o espaço em branco necessário para completar a ação, inserindo-se imaginariamente nela.

0 filme de 32 segundos é uma antítese da pressa, numa velocidade zen. As imagens foram produzidas em um templo budista na região metropolitana de São Paulo, num período não coincidente com a floração da cerejeira, conforme nos informa Paula Madureira (Diretora de Produção), no vídeo do making of ${ }^{13}$. A equipe fez, então, uma colagem manual das flores para reproduzir a floração. 0 artifício conferiu à cena uma limpidez que dificilmente se conseguiria com registros de materiais plenamente orgânicos.

A meditação incorporada ao filme também contempla a vigília. A música ganha paulatinamente tons mais fortes, que se coadunam com as ações da personagem feminina. Ela se dirige à cerejeira e nela insere um mensageiro dos ventos.

Após inserir seu mensageiro dos ventos na árvore, a personagem segura seu traje com as mãos e atravessa suavemente uma ponte. Temos aí a sinalização de uma passagem. A narrativa agora ganha uma nova travessia. A entrada visual do perfume é reforçada pelo sons que ganham força e ênfase, sem perder a tônica imersiva e sutil.

A personagem, após apanhar cuidadosamente o frasco de Floratta Cerejeira em Flor, vaporiza o perfume sobre a pele. Nesta cena, a sensualidade da imagem e seus simbolismos são reiterados, assim como os sons de ênfase do áudio. Para executar o gesto, a lentidão é utilizada, somada a expressões de prazer e entrega. Quando o perfume é vaporizado em seu pescoço com fluidez e aparente naturalidade, os olhos da personagem se fecham e sua boca se entreabre, evocando-se suavemente seu êxtase olfativo, finalizado por seu sorriso - flores de cerejeira destacam-se ao fundo. 0 vento é anunciado pelo som e pela movimentação visual do mensageiro dos ventos na cerejeira - sinaliza-se neste momento que algo aconteceu e a notícia foi trazida pelo ar.

A mulher olha para o lado, sem pressa, e com naturalidade vislumbra o efeito de sua ação que será apresentado na cena seguinte: pétalas de flores de cerejeira parecem cair do céu, contagiando os demais personagens do filme e todo o ambiente. Além da protagonista, podem-se agora vislumbrar outras canoas em torno do templo, onde surgem personagens jovens e belos.

Numa tentativa de assumirem a condição de pessoas comuns, os demais personagens destacados na imagem demonstram prazer e felicidade pela chuva de pétalas que recebem - lembremos que, na tradição japonesa da cerejeira, a princesa Sakuya, ao cair do céu, converte-se em flor. Os personagens voltam seus olhos e suas faces para o céu, e uma das mulheres da canoa estende suas mãos para fora, numa atitude de felicidade, entrega e aceitação. Todos sorriem como se estivessem recebendo graças e doses de prazer e alegria, presenciando uma cena com tons de plenitude mística, surreal, ampliando a força da protagonista e de sua magia, seu perfume. A voz cálida, límpida e feminina da locução de Sabrina Wilkins informa que "Chegaram as novas fragrâncias de Floratta. Inspiradas na tradição oriental da flor de cerejeira". Após o sorriso da personagem: "Floratta. Transforme o mundo à sua volta".14

A partir da inserção do perfume, a música vai gradativamente adquirindo mais intensidade, ritmo e força. Após vislumbrar o efeito de sua ação, a protagonista solta seu coque, metaforizando pela liberdade do cabelo a liberdade da própria personagem, após viver o encontro sinestésico e sensual com a fragrância. A mensagem parece clara, o veículo aromático inaugura o vento, a mobilidade, a liberdade, a aceitação e autoaceitação, num gesto a um só tempo narcísico, coletivo, místico e prazeroso. Nesse sentido, a cerejeira assume na narrativa o mesmo trajeto de seu simbolismo no Hanami; no filme publicitário, a fragrância convertida em flor torna-se signo de transformação e esperança. 


\section{Vaporizações: o figurino}

\section{"Todos somos descartáveis, só o ator que não. Mas, dentro dos descartáveis, os figurinistas são indispensáveis." Francisco Medeiros apud Rosane Muniz, em Vestindo os nus ${ }^{15}$}

Para que as imagens pudessem nutrir as narrativas das fragrâncias, os personagens inseridos também foram à sua maneira apresentados com uma visualidade que potencializasse não apenas a relação com o perfume e suas propostas, mas também com os simbolismos necessários ao filme. A fim de pensarmos o figurino, ressaltaremos o corpo como integrante da ação cênica, pois traje e corpo agregam-se na constituição da visualidade. Na análise da visualidade da protagonista, não podemos deixar de registrar a escolha por um corpo magro que evidencia linhas verticais, ascendentes. 0 rosto da personagem revela sutis traços asiáticos; o cabelo, mesmo em coque, apresenta movimentos comedidos; a pele da personagem foi trabalhada de forma a destacar limpidez e homogeneidade. Nesse sentido, podemos dizer que as marcas orgânicas do corpo, irregularidades, assimetrias e variações cromáticas parecem ter sido dissimuladas para se constituir uma visualidade límpida, simétrica e homogênea.

A aparente naturalidade de sua maquiagem foi, portanto, paradoxalmente conseguida pelo apagamento das variantes orgânicas. Os traços de ênfase da maquiagem parecem destacar as sobrancelhas arqueadas, índices de força, e a boca da personagem, reafirmando seu código de sedução. No making of ${ }^{16}$, há inclusive depoimentos do maquiador Sadi Consati em que ele anuncia este intento. Segundo seu relato, buscou-se evocar uma gueixa contemporânea. No âmbito do universo das gueixas, podemos considerar o domínio cuidadoso da retórica dos gestos, das mãos, bem como a ênfase dada aos lábios em sua maquiagem. Neste universo, discursivamente arte e sedução se integram, considerando-se a etimologia da palavra gueixa - pessoa que faz arte. No filme, as mãos realizam gestos cuidadosamente pensados e parecem cuidadas. As unhas receberam um esmalte muito claro, que também evoca feminilidade e limpidez.

0 traje da personagem, em certo aspecto, dialoga muito sutilmente com alguns elementos pontualmente pertencentes ao quimono, ainda que numa abordagem leve e muitíssimo dinâmica. Há um cuidadoso trabalho indicial de revelação da nuca e das costas na enorme gola estilizada que desce contornando o corpo, evidenciando delicadamente partes superiores do tronco. A faixa que envolve a cintura e pende nas nádegas, quase imperceptível na travessia da ponte, mas que confere volume ao traje, assemelha-se a um obi. Seu traje, largo, espaçoso e fluido precisa ser conduzido por suas mãos, o que confere certa especialidade à mulher e à sua roupa.

0 traje muitíssimo claro e sua modelagem ampla, numa síntese de delicadeza e leve imponência, reitera a soberbia da personagem, mas não lhe insere numa abordagem empertigada. A vestimenta permite naturalidade aos gestos, ainda que necessite das mãos para movimentá-lo. A ausência de saltos coaduna-se com a vestimenta de notas orientais e reafirma o código de fluidez e cuidadosa despretensão.

A roupa da personagem determinará a sintaxe de cada cena, seu grau de flexibilidade, volumetria, transparência, assim como determinará a gestualidade. Sobre a relação figurino e mobilidade, Geraldo Coelho Lima Júnior nos lembra que "De posse do figurino sobre seu corpo, o ator reposiciona sua atividade física, que varia em maior mobilidade ou ainda em uma restrição gestual. 0 figurino contribui para o entendimento do espaço que circunda o ator e pelo qual ele circula" (LIMA JÚNIOR, 2012, p. 194).

0 traje de cena da protagonista assemelha-se em aspectos pontuais com a estética das roupas concebidas pela vanguarda japonesa na moda, como os trajes de Issey Miyake e Yohji Yamamoto, num período posterior à fase propriamente contestatória. 
Assim, o corpo da mulher não surge objetificado, ao contrário, o traje estabelece com ela contornos próprios, numa sintaxe escultórica independente. Observa-se uma quase ausência de acessórios e ornamentos reveladores da pompa e do luxo, emanando certa integridade do sujeito que veste a peça.

Sobre o distanciamento da roupa no corpo, caracteristica muito presente no trabalho de estilistas da vanguarda japonesa, cabe destacar o texto de Fausto Viana sobre as considerações de Issey Miyake, numa menção de Abramovic sobre o estilista: "Perguntaram a ele por que suas roupas eram tão largas. Ele respondeu simplesmente que ele as fazia daquele tamanho porque queria ter espaço entre o corpo e as roupas para que o espírito pudesse ali viver" (VIANA, 2012, p. 65).

Como ornamentos poderíamos destacar os pequenos brincos de pérolas e o palito que prende seu coque - o penteado parece sugerido como algo realizado despretensiosamente pelo sujeito, deixando inclusive penderem, estrategicamente, algumas mechas de cabelo. Os brincos de pérolas, discretos e clássicos, reiteram a ideia de cuidado e feminilidade. Além disso, pode-se incluir o fato de que não criam ruídos à visualidade feminina por seu tamanho e sua tonalidade.

Na primeira tomada da mulher - close superior frontal - sua vestimenta também lembra, em certo aspecto, o traje grego com seus cortes, suas diagonais e suas pregas nos ombros e tecidos pendentes. 0 tecido claro assume um tom vaporoso, semelhante à neblina que envolve a personagem nas cenas iniciais, sugerindo um traje líquido, límpido e volátil como a fragrância. A figura feminina parece flutuar, deslizar, numa gestualidade em consonância com o ambiente etéreo de cerejeira em flor. Neste sentido, a roupa reforça a ideia de suspensão dos gestos femininos, inserindo a personagem numa condição sublime, evanescente, quase mística.

0 traje destaca a luminosidade da mulher, seu código de sedução, no qual tudo se mostra de forma sutil sem que nada seja revelado - principio elementar do erotismo. Interessante notar a transparência e a leveza do tecido que, por mais volátil, não expõe nenhum índice de intimidade, tais como possiveis sombreados de peças intimas ocultadas.

Todos os esforços de limpidez vistos no traje fazem com que ele se relacione harmoniosamente com as imagens odoriferas evocadas pelo cenário e pelo ambiente, sendo a flor de cerejeira reiteradamente afirmada. Em algumas cenas, a vestimenta movimenta-se, fazendo-se vestir o ar e seus vapores aromáticos. 0 ritmo das cenas também sugere a ideia de deslizamento contida na maciez acetinada do tecido. Assim, o destaque para o lago e sua movimentação são coerentes.

Cabe ressaltar que, após utilizar a fragrância, a personagem solta seus cabelos, uma simbologia à ideia de plenitude, liberdade, confiança e entrega. Seus cabelos, assim como seu figurino, são destacados na imagem, por meio de movimentos, signos indiciais da ação da fragrância.

Para os outros personagens que recebem a chuva de pétalas, o figurino utilizado não apresenta contrastes formais ou cromáticos. De qualquer forma, os trajes apresentados também não estão isentos de simbolismos. Eles inserem no filme uma visualidade de moda já familiar ao espectador: calça pescador, saias, blusas e camisetas.

Todos são jovens, bonitos, apresentando corpos bem distribuídos, ainda que se deseje anunciá-los como pessoas comuns. Os trajes, entretanto, não lhes promove uma carga de ênfase ou destaque visual. Há uma certa equalização no registro de visualidades distintas. As calças que lembram a modelagem estilo pescador (ainda que não se possam vê-las por completo) e as camisetas e camisas claras dos remadores parecem reiterar a relação dos personagens com o ambiente do barco, do lago e dos remos. Além das calças, outros itens de moda casual são identificados, a exemplo de camisetas regata, blusas de malha e saias.

Todos se vestem com cores claras, signos que reforçam a ideia de pacificidade, pureza, comunhão e misticismo. Os tecidos são delicados e suscetiveis à ação do vento, o que se pode ver claramente na movimentação da camisa de uma das figuras femininas que, na canoa, ergue suas mãos para a chuva de pétalas. 
0 figurino dos personagens também pode ser concebido como índice, uma ligação da narrativa fantasiosa com o mundo concreto, reafirmando o poder de sedução da fragrância que alcança o mundo factual.

0 convite "Transforme o mundo à sua volta" foi incluido como mote na linha Floratta. Alguns vídeos foram elaborados pela marca, na série "Mulheres que perfumam", a partir do convite aos consumidores para enviarem suas narrativas. Em algumas produções, foram inseridas histórias de mulheres que alteraram alguma realidade graças à sua ação e ao sentimento de esperança. A tentativa de aproximar o consumidor da marca por meio do registro da narrativa de indivíduos comuns reforça a ligação do enunciatário com seu público consumidor, dessacralizando a marca, humanizando-a. Assim, o próprio consumo ganha, no âmbito simbólico, ares de ação social. Esse dispositivo discursivo promove certa retração na concepção do produto como algo meramente mercantil, tornando-o invólucro de histórias humanas, pessoais.

Cabe destacar que a marca 0 Boticário não se insere na categoria de artigo de luxo segmentado. Ainda que possua linhas mais sofisticadas no âmbito das fragrâncias, dirige-se a uma faixa extensa do mercado consumidor. Nesse sentido, podemos considerar que a narrativa fílmica seguirá uma estética de abordagem didática em que o perfume e os seus simbolismos são continuamente reiterados, ora pela explicitude da imagem, ora pelo jogo cuidadoso e sutil de tessituras sígnicas sinestésicas.

0 filme foi concebido para divulgar as duas fragrâncias de Floratta, Cerejeira em Flore Cerejeira em Pétalas. Ambas são nitidamente apresentadas lado a lado nas imagens do filme. Para a versão em flor, a cor rosácea foi predominante tanto no frasco como na embalagem. Para a versão em pétalas, buscou-se trabalhar o tom salmão. Os aromas são nitidamente distintos, mas trazem da proposta de cerejeira notas de frescor aliadas a acordes que apresentam certa volumetria e presença.

Os nomes dados às fragrâncias também são sugestivos: da terminologia em flor, pode-se inferir notas mais suculentas e vibrantes; da versão em pétalas, podem-se inferir um aroma mais "fechado", rugoso ou concentrado. Para a reflexão sobre a importância dos nomes na relação olfativa, destacam-se as considerações de Chantal Jaquet em sua incursão no universo proustiano: "Os nomes possuem, portanto, uma potência olfativa; eles se impregnam de odores, restituem-nos ou os dissolvem não apenas sob o efeito da memória, mas também da imaginação" (JAQUET, 2014, p. 142).

Quanto à fragrância Floratta Cerejeira em Pétalas, cabe destacar que a criação desenvolvida por Alexandra Carlin foi uma das 10 finalistas do Troféu Aparício Basílio da Silva no setor de Criação Perfumística Latino-Americana Feminina. Os testes de avaliação olfativa foram realizados às cegas. ${ }^{17} 0$ nome do troféu vincula-se à figura do empresário Aparício Basílio da Silva (1936-1992). Presidente do Museu de Arte Moderna de São Paulo por nove anos, ele foi um colecionador de obras de arte e incentivador do setor, além de destacar-se como figura pioneira no ramo da perfumaria ao lançar, em 1965, a primeira produção nacional considerada como produto de perfumaria fina, a água de colônia Rastro, cujo frasco de vidro feito à mão sugeria a estética de um tubo de ensaio (CATÁLOGO DAS ARTES, 10/9/2015) ${ }^{18}$.

De qualquer forma, o mote da campanha é encenar uma fragrância nitidamente feminina que se insere numa simbologia de transformação, segundo sua inserção nos enredos da tradição oriental.

Nos créditos do filme realizado pela AlmapBBDO, até a presente data, não foram localizadas informações específicas relativas aos figurinistas - fato que sinaliza 0 quanto esses profissionais ainda carecem de reconhecimento e identificação. 


\section{Considerações finais: fechando o frasco}

Ora o esforço para decifrar pelo pensamento o que se esconde atrás da imagem e do cheiro não é sempre necessariamente coroado de sucesso. É preciso distinguir dois tipos de apelos lançados pelas sensações: os que ficarão como signos mudos para sempre e os que serão signos falantes aos quais o eu vai poder responder recolhendo-se em si mesmo para decifrar-Ihe o sentido.

Chantal Jaquet, em Filosofia do odor ${ }^{19}$

No filme selecionado, pôde-se vislumbrar que o traje de cena do perfume precisa com ele dialogar, assim como com os enredos e discursos que lhes foram vinculados. Nesse ambiente, tudo é narrativa: o perfume que nem sempre apresenta a nota da proposta temática, a representação da orientalidade - retratada segundo uma mitologia historicamente edificada pelo olhar ocidental -, assim como o poder transformador do produto. De qualquer forma, quando o consumidor interage com a fragrância, após ter estabelecido o contato com o vídeo, as imagens de limpidez, serenidade, feminilidade, fluidez e misticismo reiteradas pelo figurino prenunciarão os buquês, muitas vezes direcionando a percepção olfativa. Assim, o reino dos perfumes coincide também com aquele dos discursos: podemos dizer que cheiramos palavras, imagens, cores, narrativas e trajes. Assim, vestir o aroma na produção do figurino implicará muito mais do que definir peças e ornamentos.

$\mathrm{Na}$ concepção do figurino, inúmeros gestos criativos se tocam e convergem na [6o ] pele ou na segunda pele da personagem e de sua presença: a luz, os cenários, os acessórios, os sons - também aqueles evocados pela roupa -, os tecidos, os corpos e o imaginário - este muitas vezes completa no traje aquilo que nele não se fez. Tecer figurinos implica entrar na cozinha dos sentidos, manipulando os signos como um alquimista interdisciplinar, orquestrando notas sempre dialogadas que nunca estarão sós.

[Recebido em: 11/09/2015]

[Aprovado em: 05/10/2015]

\section{NOTAS}

[1] Versão ampliada do artigo da autora publicado nos anais do $11^{\circ}$ Colóquio Nacional e Internacional de Moda, realizado em setembro de 2015 em Curitiba /PR - Brasil.

[2] PALLASMAA, Juhani. Os olhos da pele: a arquitetura e os sentidos. Porto Alegre: Bookman, 2011. p. 12.

${ }^{[3]}$ Acerca da reflexão sobre a visão periférica, o livro Os olhos da pele: a arquitetura e os sentidos, de Juhani Pallasmaa, constitui-se um campo precioso.

${ }^{[4]}$ Ficha Técnica - Filme; Anunciante: 0 Boticário; título: Árvore; Produto: Floratta; Campanha: Floratta Cerejeira; Diretor Geral de Criação: Luiz Sanches; Diretor de Criação: Marcos Medeiros e Andre Kassu; Criação: Bruno Prosperi, Andre Sallowicz, Filipe Médice, Pedro Cavalcanti; Produtora: O2 Filmes; Produtor Executivo: Rejane Bicca; Direção: Alex Gabassi e Ricardo Della Rosa; Fotografia: Ricardo Della Rosa; Montador / Editor: Sabrina WilkinsFinalizadora: 02 filmes; RTVC: Vera Jacinto, Ana Paula Casagrande, Rafael Motta e Thiago Bueno; Trilha: Tesis; Locutor: Sabrina Wilkins; Atendimento: Camila Massari, Daniela Teixeira, Thamy Alegria, Luana Segatto, Fernanda Ferreira, Stefanie Giannini; Planejamento: Cintia Gonçalves, Maria Anita Ferreira, Valter Bombonato, Bruno Chenque, Murilo Oliveira; Midia: Paulo Camossa, Flavio de Pauw, Thelma Marques, Carlos Jordão; Aprovação: Andrea Mota, Ana Ferrell, Daniele Trito, Luciane Vertemati, Caroline Mazete. (Disponivel em: http:// www.almapbbdo.com.br/index.php\#section=trabalhoctid=995. Acesso em: 14 maio 2015.)

[5] JAQUET, Chantal. Filosofia do odor. Rio de Janeiro: Forense Universitária, 2014. p. 222.

${ }^{[6]}$ Disponivel em: <http://www.boticario.com.br/floratta-cerejeira-em-flor-des--colonia-100ml-19679/ p>. Acesso em: 15 maio 2015.

[7] Disponivel em: <http://www.boticario.com.br/floratta-cerejeira-em-flor-des--colonia-100ml-19679/p>. Acesso em: 16 maio 2015.

${ }^{[8]}$ Disponivel em: <http://www.osmoz.com.br/enciclopedia/materiasprimas/frutal/143/cereja-prunus-cerasus>. Acesso em: 15 maio 2015.

[9] Disponivel em: <http://www.naritadesign.com.br/cases/0\%20botic\%c3\%a1rio/floratta/18>. Acesso em: 15 maio 2015.

[10] Disponivel em: <http://www.almapbbdo.com.br/index.php\#section=trabalhottid=995>. Acesso em: 15 maio 2015. 
[11] Link para as imagens: <http://www.almapbbdo.com.br/index.php\#section=trabalhoctid=995>. Acesso em: 15 maio 2015.

[12] Link para visualização do vídeo: <https://www.almapbbdo.com.br/index.php\#section=trabalhoctid=995>. Acesso em: 10 set. 2015

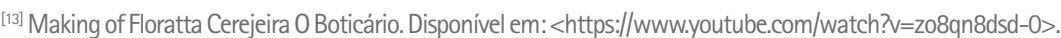
Acesso em: 15 maio 2015.

[14] Disponivel em: <http://www.almapbbdo.com.br/index.php\#section=trabalhoctid=995>. Acesso em: 15 maio 2015.

[15] MUNIZ, Rosane. Vestindo os nus: o figurino em cena. Rio de Janeiro: Senac Rio, 2004. p. 67.

${ }^{[16]}$ Making of Floratta Cerejeira O Boticário. Disponivel em: $<$ https://www.youtube.com/watch?v=zo8qn8dsd-0>. Acesso em: 15 maio 2015.

[17] Disponivel em: <http://www.cosmeticanews.com.br/leitura.php?n=conheca-as-criacoes-perfumisticasque-concorrem-ao-trofeu-aparicio-basilio-da-silva-do-premio-atualidade-cosmeticactid $=4647>$. Acesso em: 15 maio 2015

[18] Disponivel em: <http://www.catalogodasartes.com.br/detalhar_biografia_artista.asp?idartistabiografia=7640>. Acesso em: 10 set. 2015.

[19] JAQUET, Chantal. Filosofia do odor. Rio de Janeiro: Forense Universitária, 2014. p. 161.

\section{REFERÊNCIAS}

ALMAPBBDO. Disponivel em: <www.almapbbdo.com.br>. Acesso em: 15 maio 2015.

CATÁLOGO DAS ARTES. Disponivel em: <www.catalogodasartes.com.br/Detalhar Biografia Artista. asp?idArtistaBiografia=7640>. Acesso em: 10 set. 2015

COSMETICA NEWS. Disponível em: <www.cosmeticanews.com.br>. Acesso em: 15 maio 2015.

JAQUET, Chantal. Filosofia do odor. Trad. Michel Jean Maurice Vicent e Maria Angela Mársico da Fonseca Maia. Rio de Janeiro: Forense Universitária, 2014

LIMA Júnior, Geraldo Coelho. Pele do ator, pele da personagem: entre design de moda e figurino, reflexões para a cena contemporânea. IN: VIANA, Fausto; MUNIZ; Rosane. Diário de pesquisadores: traje de cena. São Paulo: Estação das Letras e Cores, 2012. p. 185-200.

MUNIZ, Rosane. Vestindo os nus: o figurino em cena. Rio de Janeiro: Senac Rio, 2004.

NARITA Design. Disponível em: <www.naritadesign.com.br>. Acesso em: 15 maio 2015.

O BOTICÁRIO. Disponível em: <www.boticario.com.br>. Acesso em: 15 maio 2015.

OSMOZ. Disponivel em: <www.osmoz.com.br. Acesso em: 15 maio 2015

PALLASMAA, Juhani. Os olhos da pele: a arquitetura e os sentidos. Trad. Alexandre Salvaterra. Porto Alegre: Bookman, 2011.

PESSOA, Fernando. O eu profundo e os outros eus. Rio de Janeiro: Nova Fronteira, 1974. p. 146.

VIANA, Fausto. Os trajes de Marina Abramovic: a performer... e o flerte com a moda. IN: VIANA Fausto; MUNIZ, Rosane. Diário de pesquisadores: traje de cena. São Paulo: Estação das Letras e Cores, 2012. p. 51-66. 